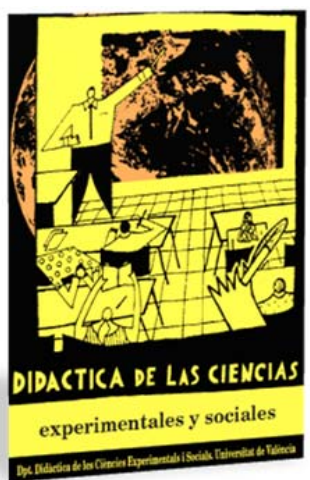

\title{
La Guerra Civil en los libros de visitas. Fuentes de conocimiento sobre formación y participación ciudadana
}

\author{
The Civil War through the Guestbooks as \\ sources of knowledge on training and civic \\ participation
}

DOI: $10.7203 / D C E S .34 .10704$

\author{
Santiago Jaén Milla \\ Universidad de Jaén \\ sjaen@ujaen.es
}

ORCID iD: http://orcid.org/0000-0002-8913-8959

RESUMEN: El trabajo realiza una aproximación a los libros de visitas o firmas de un refugio antiaéreo construido durante la Guerra Civil en Jaén, con la pretensión de valorar la opinión y el conocimiento que escolares, turistas y visitantes en general, tienen hoy en día del conflicto bélico, y apreciar esas opiniones como actos de participación ciudadana sobre el conflicto, el elemento patrimonial visitado y la musealización realizada en el interior del espacio, entre otras cuestiones.

Palabras Clave: Libros de visitas, Guerra Civil, Jaén, participación ciudadana, patrimonio.

ABSTRACT: This study intends to make an approach to the guestbooks of an antiaircraft shelter built during the Civil War in Jaen, trying to assess the opinion and knowledge that scholars, tourists and visitors in general, have of the war nowadays, and to appreciate these opinions as acts of civic participation on the conflict, on the patrimonial element visited and the musealization made within the space, among other issues.

KEYwORDS: Guestbooks, Civil War, Jaén, Civic Participation, Heritage.

Fecha de recepción: octubre de 2017

Fecha de aceptación: febrero de 2018 


\section{INTRODUCCIÓN}

La Guerra Civil Española es un hecho histórico que sigue formando parte del debate público y político en nuestro país. El paso del tiempo y la desaparición de sus protagonistas -de las generaciones que vivieron y protagonizaron el conflicto- no ha impedido que su recuerdo siga provocando dolor, indignación y mucha incomodidad en una parte importante de la sociedad española. Sin duda, el elevado número de desapariciones y fosas comunes han contribuido a un deseo irrefrenable por conocer la historia del enfrentamiento y por otro lado, ha provocado un debate en la sociedad española sobre la necesidad de recuperar y dignificar los cuerpos de los fusilados por el bando vencedor.

Dentro de este proceso podemos enmarcar el conocimiento, recuperación y musealización de numerosos vestigios del conflicto, que se están convirtiendo en espacios memoriales, turísticos y de formación en valores de ciudadanía, a imagen y semejanza del proceso experimentado desde los años cuarenta en numerosos países europeos.

Los libros de visitas -o de firmas- no han sido utilizados por los historiadores ni los Didactas de las Ciencias Sociales como fuentes de conocimiento de ambas disciplinas científicas. Y esto a pesar de que todos y todas hemos visitado museos, centros de interpretación y espacios patrimoniales, y no hemos terminado la visita sin dejar nuestra firma, e incluso nuestra opinión, sobre lo visitado. Además, para la mayor parte de los visitantes, la firma suele estar precedida de un pequeño tiempo de reflexión -buscamos dejar mensajes y reflexiones impactantes y que hagan pensar a un posible lector de los mismos- y de una lectura rápida de las reflexiones que han dejado otros firmantes, en donde buscamos inspiración para nuestro mensaje valorando la opinión expresada por otras personas. Hemos llegado incluso a emocionarnos o indignarnos con lo leído en ese libro de firmas y pensamientos. Como señaló Ayán Vila (2015, p. 210), el convencimiento de que nadie leería jamás esas reflexiones, es lo que ayuda a comprender la espontaneidad, naturalidad y franqueza de esa escritura. No obstante, nosotros consideramos que muchos y muchas nos esforzamos en dejar por escrito una frase o una reflexión importante, porque en el fondo queremos y deseamos que alguien la lea en algún momento posterior.

Para nosotros los libros de firmas pueden constituir una importante fuente de conocimiento sobre los hechos históricos a los que alude la exposición o el espacio visitado, tanto de los acontecimientos ocurridos en el pasado y en los que se enmarca el vestigio patrimonial, como de la gestión del mismo en el presente, así como para valorar la formación en valores democráticos de la ciudadanía.

\section{MARCO TEÓRICO}

\subsection{Didáctica de la Guerra Civil Española: patrimonio y formación en valores de ciudadanía}

Para los didactas de las Ciencias Sociales, el patrimonio de la guerra civil es una fuente histórica especialmente emotiva. Además, enriquece y genera conocimiento, motiva al alumnado y facilita la asunción de valores de ciudadanía. Como señalan Rojo Ariza et al. (2014), lo tangible emociona, y la emoción permite y fomenta el aprendizaje. Además, la propia materialidad que tiene el patrimonio de la Guerra Civil le aleja de la praxis tradicional, lo que nos obliga a apostar por llevar a cabo propuestas investigativas que incluyan visitas didácticas al patrimonio bélico, porque entendemos que el aprendizaje vivencial, el que se experimenta, es infinitamente más productivo que el que se adquiere en el aula a partir de las explicaciones del docente, independientemente de la metodología que éste utilice.

Cuando el alumnado pasea por la historia, pone imágenes a los datos que se estudian en los manuales, aumenta la capacidad de retención del conocimiento adquirido, provoca reflexión sobre el hecho histórico, fomenta la investigación personal y sobre todo, hace que el alumnado dote de 
una dosis de realidad a los hechos descritos en los libros. Asimismo, cuando el alumnado y la ciudadanía en general se acercan a estos vestigios, se afianzan los pensamientos y actitudes positivas sobre la resolución pacífica de los conflictos, sobre las normas y pautas de convivencia pacífica.

Coincidimos con Feliu Torruella y Hernández Cardona (2013, p. 11), en que todas las propuestas para trabajar la Guerra Civil en el aula, o fuera de ella, deben contar con una carga de educación en valores (científicos, cívicos y democráticos), y tener como base del trabajo "la condena de todo tipo de barbarie totalitaria".

\subsection{Educación para la ciudadanía y educación para la Participación ciudadana}

La educación ciudadana -muy especialmente en su aspecto formal- tiene que tener como objetivo fundamental generar una ciudadanía activa y participativa en la sociedad. Las decisiones sobre todo lo que nos afecta en nuestra vida cotidiana no pueden ser ajenas a la sociedad, ni deben ser decisión única de la clase gobernante. La ciudadanía debe estar atenta y vigilante para que la gestión de lo público obedezca a criterios de justicia e interés general, y no sólo a intereses económicos y particulares. Entre otras cuestiones, la ciudadanía actual debe decidir qué debemos hacer y cómo debemos gestionar un patrimonio tan sensible -emocionalmente hablando- como es el de la guerra civil. Por todo esto, estamos de acuerdo con Sant Obiols y Pagès Blanch (2012, p. 363), quienes señalaron que la participación ciudadana implica "el protagonismo de la ciudadanía en la toma de decisiones sobre su futuro personal y colectivo", máxime, cuando muchos dirigentes suelen actuar una vez que la sociedad civil les empuja y les marca el camino sobre las decisiones que deben tomar, bien desde la calle o con la presión que ejerce la opinión pública en forma de encuestas y estudios de opinión.

¿Qué entendemos por educación para la participación? Según García Pérez y De Alba Fernández (2007), la participación es una dimensión de la educación para la ciudadanía. Estamos de acuerdo en que la participación está ligada al compromiso y la transformación social, a la formación en valores y actitudes democráticas, especialmente relacionadas con la educación para la paz, "consolidando así el aprendizaje de la ciudadanía como una construcción compleja y garantizando la transferencia de lo aprendido al contexto ciudadano real" (p. 248).

La ciudadanía del siglo XXI debe ser activa, participativa y comprometida, y no sólo en su entorno cercano, sino, como apunta García Pérez (2009, p. 6), hay que apostar por un modelo de ciudadanía planetaria, y no sólo nacional o patriótica "profundamente arraigada en la sociedad y fomentada desde la escuela tradicional", porque los problemas más importantes a los que se enfrentan nuestras sociedades tienen causas y consecuencias planetarias. Por consiguiente, la enseñanza de las Ciencias Sociales tiene que promover, además de la adquisición de conocimientos sobre el pasado y el presente, que el alumnado pase de la reflexión a la acción, desde la valoración de las situaciones a la toma de decisiones, y que educar para la participación ciudadana implica "educar para la intervención social, para el cambio social, para mejorar la convivencia democrática, para promover la igualdad y justicia social, para denunciar las desigualdades y defender los derechos humanos" (De Alba, García y Santisteban, 2012, pp. 13-14).

Por otro lado, y siguiendo lo manifestado por Bonil, Junyent y Pujol (citados por García Pérez y Moreno, 2013, 14-15), el entorno y la ciudadanía están en constante relación por lo que es imprescindible crear nuevos espacios que fomenten la "participación, la concienciación, la educación y la capacitación de la ciudadanía", valores éstos que son de fácil adquisición mediante el uso didáctico de los vestigios bélicos de la Guerra Civil.

Y por último, como señalan Lucas y Estepa (2016, p. 94), la interpretación que el alumnado hace in situ del patrimonio, les lleva a mostrar interés y preocupación por la solución de los problemas de gestión y conservación del patrimonio, lo que se denomina compromiso de emotividad. 


\subsection{Análisis crítico del discurso}

Este trabajo también es deudor del tipo de investigación conocido como Análisis Crítico del Discurso (en adelante ACD), que aunque no tiene un marco teórico unitario, como bien ha señalado Van Dijk, se centra en el análisis discursivo del texto y el habla (por ejemplo, del discurso político) estudiando "la forma en la que el abuso de poder y la desigualdad social se representan, reproducen, legitiman y resisten en el texto y el habla en contextos sociales y políticos". Puede ser además definido como un movimiento social de analistas discursivos políticamente comprometidos (Van Dijk, 2016, p. 204).

Los investigadores críticos asumen, según este autor, posiciones explícitas en las cuestiones sociales y políticas, y no sólo como ciudadanos, sino también como investigadores que aspiran a producir conocimiento, y se comprometen en prácticas profesionales que pueden ser útiles dentro de procesos de cambio político y social (Van Dijk, 1999). Como señala Bañón (2008, p. 32), el ACD no sólo se ocupa del producto, sino también del proceso de elaboración y recepción del producto. O dicho de otro modo, incide en cuestiones tan importantes como la discriminación en el acceso que sufren los actores sociales (personas y colectivos) implicados en los foros de debate en los que se plantean, por ejemplo, cuestiones relacionadas con la gestión o la consecución de medios útiles en relación con temas también relevantes desde el punto de vista social, como pueden ser los procesos migratorios, salud y medio ambiente; a esta lista nosotros añadimos los debates políticos sobre la gestión del patrimonio bélico, el patrimonio relacionado con la Guerra Civil Española. Coincidimos con Bañón (2008) en que la valoración a través del discurso es un elemento fundamental de todo debate social.

En este trabajo nos vamos a centrar en varias cuestiones, algunas de ellas señaladas por Van Dijk (2016), como las principales dimensiones del ACD y de los estudios discursivos en general: Historia, política y cultura, lo que relaciona discurso, cognición y sociedad (p. 206). Los usuarios del lenguaje, añade Van Dijk, en tanto a su función como actores sociales, poseen ambos tipos de cognición personal y social (memoria individual, conocimiento y opiniones), así como aquellas compartidas con miembros de su grupo o cultura en su totalidad" (p. 207).

\section{El refugio antiaéreo de la Plaza de Santiago de JaÉn}

El bombardeo que sufrió la ciudad el 1 de abril de 1937, considerado el “Guernica andaluz”, que sólo tenía como objetivo militar causar el mayor daño posible entre la población civil, para minar su moral y la del ejército republicano, provocó la muerte de 157 personas, 57 hombres, 36 mujeres y 64 menores de edad. La construcción de refugios antiaéreos en la ciudad comenzó nada más producirse este dramático bombardeo. En la ciudad de Jaén, que contaba en 1937 con 40.000 habitantes, se construyeron 35 refugios públicos entre 1937 y 1939. Según Antonio y Jorge Vera (2000, pp. 329-331), la ciudad de Jaén fue una de las ciudades españolas que más refugios construyó en relación con el número de habitantes.

El refugio de la Plaza de Santiago fue abierto al público en el año 2011, tras ser acondicionado y musealizado. La pretensión que tuvimos quienes participamos en la musealización de este refugio fue elaborar un discurso narrativo, que apoyándose en diversos recursos didácticos (fotografía, documentación original, prensa escrita, poesías...), permitiera a todos los visitantes contextualizar el espacio en el tiempo, comprender por qué y para qué se construyó, e invitar a la reflexión sobre las terribles consecuencias que tiene para la vida humana, especialmente para la población civil, cualquier conflicto bélico. De esta forma, se elaboró una exposición teniendo en cuenta algunos de los principios básicos de la museografía didáctica señalados por Llonh y Santacana (2011, pp. 14-15 y 39-40): había un guión narrativo, con un carácter emotivo y trágico; se estimuló el pensamiento racional y las emociones; se hacen preguntas implícitas a los visitantes; 
se utilizan recursos variados; se trabajan los conceptos, pero también los procedimientos y las actitudes.

La intervención realizada consistió en la instalación de paneles explicativos que sitúan al visitante en el contexto de la Guerra Civil y los primeros bombardeos sobre poblaciones civiles; exposición cronológica de documentos históricos, que permiten seguir los distintos momentos del bombardeo de Primero de abril, como la orden militar dictada por Queipo de Llano; las impresiones y reflexiones que de esa acción elaboraron escritores como Miguel Hernández y Rafael Porlán; fotografías de época que recogen las consecuencias que provocó el bombardeo franquista en la ciudad, etc. Asimismo, en varios paneles aparecen las decisiones que adoptaron las autoridades civiles y militares de la ciudad tras esa acción militar de los sublevados: construcción inmediata de varios refugios antiaéreos, así como las represalias y posterior fusilamiento de 130 presos derechistas que estaban recluidos en diversas cárceles de la ciudad. Entre lo más destacado de la musealización está el hecho de que no hay información cerrada y acabada por el equipo de trabajo, sino que cualquier visitante puede recomponer los hechos ocurridos siguiendo la documentación original presentada, lo que contribuye además al conocimiento sobre la ciencia histórica, sobre cómo los historiadores construyen la historia.

Era obligado en el refugio un recuerdo a las víctimas, que en su mayoría eran mujeres y niños, por lo que se incluyó en la exposición un panel con el nombre, apellidos y edad de los fallecidos.

También el refugio cuenta con un espacio para la reflexión -aparte de los libros de firmas- en la que los adultos y especialmente, los niños y niñas que visitan este subterráneo, pueden expresar mediante la palabra o el dibujo lo que para ellos ha supuesto la visita, lo que piensan de la Guerra y sus consecuencias. Los dibujos son exhibidos en unos corchos preparados para este fin. Este espacio para la reflexión está acompañado por una poesía de Miguel Hernández, “Tristes Guerras”, que es todo un alegato a favor de la resolución pacífica de los conflictos.

Este refugio ha recibido desde su apertura en febrero de 2011 abundantes visitas, tanto de ciudadanos de Jaén, como de turistas llegados desde diversos puntos del país y del resto del mundo, así como de numerosos escolares de los distintos niveles educativos de la ciudad.

Según datos oficiales facilitados por la Concejalía de Turismo del Ayuntamiento de Jaén, de 2013 hasta julio de 2017 visitaron este espacio 23.846 personas, por lo que estamos hablando de un espacio que tiene una gran demanda por parte de la ciudadanía, y lo que es más importante para nosotros, de centros escolares de la ciudad.

Respecto a los centros educativos, entre noviembre de 2012 y noviembre de 2013, en el marco de un itinerario cultural que ofertaba la Concejalía de Cultura del Ayuntamiento de Jaén, 773 alumnos y alumnas de colegios públicos, concertados e incluso, uno privado, visitaron el espacio. La mayor parte de este alumnado pertenecía al tercer ciclo de Educación Primaria. Estamos de acuerdo con López Facal (2011, p. 5), cuando afirma que los conflictos no se aprenden a gestionar de forma espontánea, por lo que se hace necesario llevarlos al aula, para que sean trabajados y analizados y "desarrollar la capacidad de defender puntos de vista propios basados en datos y argumentos racionales”, y que sirvan para respetar la opinión del oponente.

En definitiva, el refugio antiaéreo de la Plaza de Santiago de Jaén es mucho más que un vestigio del pasado que nos habla de un conflicto bélico: es un espacio de memoria colectiva, que nos sitúa ante la barbarie humana, y también y como señaló acertadamente Ayán Vila para las Cuevas de Altamira (2015, p. 13), es un espacio sentimental, patrimonial, museístico y político.

\section{ESTUDIO Y ANÁLISIS DE LOS LIBROS DE VISITAS DEL REFUGIO DE SANTIAGO}

\subsection{Objetivos del estudio}

- Valorar la opinión que los visitantes tienen sobre el espacio patrimonial (refugio antiaéreo).

- Estimar la opinión que tienen sobre la musealización del refugio. 
- Establecer categorías de análisis cualitativo a partir de las opiniones expresadas en los libros de visitas.

- Valorar si los libros permiten vislumbrar que el espacio y la musealización del mismo contribuyen a la formación en valores de ciudadanía.

- Evaluar si los libros permiten valorar la participación ciudadana sobre el elemento patrimonial en particular, y sobre los vestigios de la guerra en general.

- Contribuir al debate sobre la apertura a la ciudadanía de los vestigios bélicos de la Guerra Civil Española.

Este texto estudia y analiza -desde un punto de vista cualitativo- las opiniones expresadas por numerosas personas que tras visitar el refugio antiaéreo quisieron dejar por escrito un mensaje sobre lo experimentado en su interior. Es por tanto un estudio intergeneracional, ya que no ha sido posible disociar por edades u otros parámetros (culturales, socioeconómicos) las expresiones plasmadas en los dos libros de visitas examinados. El primero de ellos -de 196 páginas- abarcó el periodo transcurrido entre el 27 de febrero de 2011 (día en que fue abierto al público el espacio) y noviembre de 2014; mientras que el segundo -148 páginas, abarca el espacio temporal que transcurre entre finales de noviembre de 2014 y junio de 2016.

Siguiendo los planteamientos de la línea de investigación conocida como ACD hemos establecido las siguientes categorías de análisis: Historia, Política y Cultura.

La Historia, según Joaquín Prats (2011, pp. 13-14), es una disciplina científica que mediante el análisis de problemas de las sociedades pasadas, "ayuda a comprender la complejidad de cualquier acontecimiento, de cualquier fenómeno social y político actual, así como de cualquier proceso histórico mediante el análisis de causas y consecuencias".

Respecto a la Política, el profesor Sodaro (2004, p. 1), señala que "es el proceso por el que las comunidades persiguen objetivos colectivos y abordan sus conflictos en el marco de una estructura de reglas, procedimientos e instituciones, con el objetivo de alcanzar soluciones y adoptar decisiones aplicables por la autoridad estatal (en sus diferentes niveles político-administrativos) al conjunto de la sociedad”. Además, como señala Sodaro, la política implica a varios agentes como son los ciudadanos, las organizaciones y los gobiernos, y apunta que abordar la solución de un problema no implica resolverlo (p. 2).

Por último, hemos tomado la definición de Cultura que proporcionó en 1982 la UNESCO (Organización de las Naciones Unidas para la Educación, la Ciencia y la Cultura): conjunto de rasgos distintivos, espirituales y materiales, intelectuales y afectivos, que caracterizan a una sociedad o grupo humano. Este concepto engloba además todo lo relacionado con los valores, tradiciones, creencias y la capacidad de reflexionar sobre sí mismo que tiene el ser humano. Para nosotros tienen especial importancia los valores relacionados con una sociedad democrática: respeto, solidaridad, libertad, igualdad, justicia...

Por otro lado, también vamos a resaltar las afirmaciones que según hemos establecido en el marco teórico, podemos identificar como propias o características de la educación para la participación.

\subsection{Categorías de análisis}

\section{Historia}

En esta categoría incluimos diversas cuestiones relacionadas con el conflicto bélico que se desarrolló entre julio de 1936 y marzo de 1939, como por ejemplo el rechazo inicial al Golpe de Estado de julio de 1936, la pérdida de los incipientes derechos y libertades democráticos y republicanos al término de la guerra, las alusiones a los vencidos o fusilados en la posguerra, así como el bombardeo franquista que sufrió la ciudad de Jaén el uno de abril de 1937. A pesar de contar con numerosas reflexiones sobre la guerra y los culpables del golpe de Estado y la brutal 
represión posterior por parte del bando fascista, no hemos reconocido sentimientos ni deseos de venganza o revancha. Únicamente constan peticiones de justicia y recuerdo (homenajes) para las víctimas y los que lucharon por la libertad y la democracia republicana.

No obstante, algunos firmantes reniegan de la equidistancia, neutralidad o reparto de culpas que hacen algunos historiadores, (e incluso docentes de cualquier nivel educativo, añadimos nosotros) que afrontan la Guerra Civil en sus aulas sin aproximarse a las causas del conflicto, sin entender las lógicas y contradicciones de los protagonistas, ya que sólo se centran en el espacio temporal del conflicto, el desarrollo y las batallas más significativas, y las consecuencias del mismo. De esta forma, entendemos que no se genera conocimiento productivo y duradero sobre la guerra civil, pues lo que no se conoce en profundidad o se obvia directamente, especialmente lo relacionado con los orígenes y causas del hecho histórico, no puede contribuir a construir un futuro mejor.

Como didactas de las Ciencias Sociales nos congratula que sean numerosos los visitantes que entienden el refugio y la historia que encierra como un lugar de aprendizaje -de enseñanza de la historia- así como de formación ciudadana y transformación social. Y a esto contribuye el espacio en sí y la musealización del mismo.

Algunas aportaciones refieren dos cuestiones muy importantes para nosotros: la evidencia que nos ofrecen estos vestigios de la Guerra Civil para confirmar que hubo una guerra en nuestro país, lo que facilita el trabajo con nuestro alumnado, que puede ir a los escenarios de la historia -durante el desarrollo de salidas o itinerarios didácticos- y por otro lado, y relacionado con lo anterior, estos espacios nos ofrecen la posibilidad de poder imaginar el horror vivido durante el conflicto. Justamente, la empatía es una de las cuestiones que más se trabaja cuando se visitan los refugios antiaéreos, porque estos vestigios nos permiten imaginar el miedo y el sufrimiento vivido por quienes tuvieron que refugiarse en ellos. A este respecto, hemos podido comprobar que la visita al espacio no deja indiferente a nadie y hace aflorar todo tipo de sentimientos: tristeza, rabia, dolor (especialmente por los niños y niñas, víctimas inocentes de la guerra y los bombardeos), emoción, horror, pero también la empatía con todos y todas las que sufrieron la guerra, y muy especialmente, con los que tuvieron que refugiarse en estos subterráneos.

Algunos ejemplos de lo señalado por los visitantes:

"En memoria de quienes murieron defendiendo la libertad y la democracia".

"Qué aquellos que lucharon por la libertad no sean olvidados. Que las nuevas generaciones sean guardianes de dicha libertad”.

"Les robaron la vida a un país entero. Viva la República. Salud”.

“¿Qué injusta es la vida para algunas personas luchadoras!”.

"Que no se olviden las atrocidades por esta guerra causadas por los fascistas”.

"Vergüenza hemos sentido por la barbarie fascista".

"Impresionado por la visita y del daño causado a Jaén por el fascismo".

"A mis tíos fallecidos en ese bombardeo, que arrancó sus vidas cuando aún no sabían cómo luchar por ellas”.

"Quiero agradecer el reconocimiento de una víctima inocente de aquel bombardeo de 1 de abril de 1937, a la tía abuela de mi madre, Carmen García Garrido, que esperaba cola para comprar carbón para poder cocinar...”

"Por esos niños que no les dejaron vivir".

"A mis primas que murieron en la Fontanilla, Clara y María con 7 años y 5 años, para que esto no ocurra nunca más”.

"En memoria de los fallecidos y en especial de María Cruz Campos, hermana de Sebastián Cruz Campos, padre de mi marido”.

"A la memoria de mi abuelo Cosme, fusilado por los fascistas en 1942".

"Mi abuelo fue fusilado en La Carolina...siempre te recordaremos”. 
“A todos los desaparecidos que tengan el descanso eterno y para los que aún viven un merecido homenaje”.

"Por un futuro aprendiendo de nuestro pasado, espero que este refugio lo vea mucha gente para aprender de él y de sus historias pero que no se tenga que utilizar por necesidad”.

"El pueblo que olvida su historia está condenado a repetirla. No olvidemos".

"Porque la Historia es importante para evolucionar en el futuro. Nunca la olvidemos".

"Para que nunca olvidemos lo cafres que los seres humanos podemos llegar a ser".

"Qué la historia y el patrimonio nos enseñe a convivir y a no cometer errores".

"Espero que este lugar sea un arma contra el olvido".

"Qué el recuerdo nos haga pensar en el futuro".

“Ojalá aprendamos de lo ocurrido".

"La falta de conciencia histórica nos impide valorar lo que tenemos".

"Que nunca se nos olvide que existió una guerra. Mi madre se refugió aquí”.

"...el estar en este refugio nos ha hecho simplemente pensar lo horroroso que pudo ser aquella situación. La piel de gallina el estar aquí”.

"Conmovedor recuerdo de la barbaridad humana".

"Impresionante la sensación, que nunca se repita".

"Qué pequeño y estrecho. Pobres personas".

"Estuve aquí y me horroricé".

"Nunca había visitado uno, y la verdad es que impresiona. Cuanto miedo pasarían las personas que vivieron esta cruel guerra”.

“¿Y esto por qué no sale en los libros de historia que tanto nos hacen estudiar?”.

“Nada de neutralidad, más bien denunciar el horror, lo produzca quien lo produzca”.

Por otro lado, en los escritos que hemos incluido en esta categoría reconocemos algunas de las características que definen la educación para la participación: compromiso e interés por el conocimiento histórico, fomento de los valores y principios democráticos, y reconocimiento de estos espacios como lugares de aprendizaje o de transformación social.

\section{Política}

Aunque la sociedad civil tiene mucho que decir y hacer por conocer, conservar y valorizar nuestro patrimonio, no es menos cierto que la decisión de proteger, conservar y abrir a la ciudadanía estos espacios de la guerra sigue siendo aún una cuestión de voluntad política, de ahí que numerosos ciudadanos agradezcan en los libros de firmas la apertura del espacio memorial a las autoridades locales, especialmente, a la alcaldesa Carmen Peñalver, en cuyo mandato se llevó a cabo la inauguración y apertura del refugio. A este respecto, el refugio de la guerra civil ha sido objeto de enfrentamiento político en la ciudad de Jaén, pues al poco tiempo de inaugurarse fue cerrado al público, coincidiendo con el cambio de signo que se produjo en la ciudad con las elecciones municipales de mayo de 2011. El nuevo equipo de gobierno señaló que no pretendía clausurarlo pero era necesario solventar una serie de deficiencias en el espacio, relacionadas con filtraciones de agua y alumbrado eléctrico, por lo que se mantuvo cerrado más de un año. Por este motivo, surgió una corriente en la ciudad que reclamaba a las autoridades que reabrieran el espacio, y empujaba a la oposición de izquierdas en el consistorio a que presentaran proposiciones en el pleno para reabrirlo. Es por esto por lo que entendemos que numerosas personas señalan en los libros de visitas analizados su deseo de que este lugar permanezca abierto y en condiciones de ser visitado, deseos que podemos valorar como ejemplo de participación ciudadana, que reacciona y se opone a las decisiones adoptadas por las autoridades políticas en un momento determinado, respecto a un patrimonio tan emotivo y sensible como es un refugio de la Guerra Civil. 
Asimismo, muchos visitantes indican el camino a seguir por las autoridades: trabajar por la ciudad, proponer y desarrollar iniciativas de todo tipo -incluidas las culturales- y preocuparse por el patrimonio que hay en el subsuelo de la capital. Algunos firmantes incluso van más allá y reclaman -como hiciera Miguel Hernández durante la Guerra en su famoso poema Aceituneros- que la ciudad de Jaén despierte de su apatía e indiferencia, y reclame a las administraciones inversiones para acabar con el olvido histórico que la ciudad y toda la provincia sufren por parte de las administraciones central y autonómica. Es llamativa la alusión en los textos a la responsabilidad que tiene toda la ciudadanía de Jaén -y no sólo la clase política- en el conocimiento y conservación de estos espacios.

Y tampoco faltan referencias al movimiento por la recuperación de la memoria histórica, y el apoyo y agradecimiento a las instituciones que promueven las políticas memorialistas. Además, se afirma en varios testimonios que la memoria histórica es lo contrario al olvido, y que el olvido es el camino a la guerra. A este respecto, hay que destacar que el movimiento memorialista de Jaén presionó para que se conocieran y valorizaran estos vestigios de la guerra, lo que fue determinante para que este refugio se conservara y no fuera derruido en beneficio de la construcción de un aparcamiento subterráneo como demandaban algunas asociaciones de vecinos.

Ejemplos:

"Gracias Carmen. Gracias por la memoria de mi abuelo, al que no me dejaron conocer". “Eso es lo que tiene que hacer cosas por Jaén”.

"Gracias por haber restaurado el refugio y que se pueda admirar y darnos cuenta de la suerte que tenemos de estar viviendo en el año 2011”.

"Gracias a todas las personas que han colaborado y ayudado a sacar a la luz trozos de nuestra historia”.

"Gracias por recuperar este refugio para preservar la memoria de tantos que sufrieron desde este Jaén republicano”.

“Gracias al equipo de gobierno por recuperar parte de nuestra historia”.

"Una verdadera pena que los ciudadanos de Jaén nos encontremos con tantos sitios históricos cerrados. BASTA YA".

"Qué Jaén por fin despierte y saque a la luz estas maravillas perdidas”.

"Me ha gustado mucho la visita. Soy de Jaén y desde luego me agrada mucho que se habiliten centros como el refugio antiaéreo. Bravo por la iniciativa”.

"¡Hemos descubierto un trocito de historia! Gracias por cuidar la historia de nuestra ciudad”.

"Está muy bien rehabilitado, me ha gustado mucho y tendríamos que recuperar más historia de Jaén”.

“Me alegro que se recupere este refugio así como los que queden en Jaén”.

"Gracias por mantener la memoria de la historia tan horrible de este país".

"Muchas gracias por la labor de mantener la memoria”.

"Agradecida a quienes desde sus responsabilidades visibilizan y hacen que estos espacios se conozcan y se reavive esa memoria histórica que tantos quieren silenciar. Gracias”.

"La memoria histórica tiene que prevalecer no el Valle de los caídos”.

“Con olvido no habrá paz”.

"Que la gente de Jaén aprecie y sepa conservar este lugar para siempre”.

"Espero que este lugar sea un arma contra el olvido".

"Memoria contra el olvido".

“Espero que este sitio se siga conservando".

“Cuidarlo con mucho cariño”. 
Respecto a la educación para la participación podemos identificar varias características en esta categoría de análisis: compromiso de emotividad (que nos habla de compromiso con la conservación y recuperación de estos espacios), y compromiso con el interés y conocimiento por nuestro pasado histórico.

\section{Cultura}

Con mucha diferencia respecto a las demás opiniones recogidas en los libros de visitas, las que más se repiten entre los firmantes son las relacionadas con la paz. Este deseo es manifestado por muchos niños que visitan el espacio con centros escolares o en compañía de sus familias. Los visitantes expresan su esperanza de que los refugios no tengan que volver a ser utilizados y sólo sirvan como espacio de recuerdo -contra el olvido-, como espacios de formación ciudadana didáctica-, y para visitas turísticas. Hacen incluso distinción entre quienes se consideran culpables de las guerras (políticos y militares) y aquellos que sufren sus consecuencias (población civil y la ciudadanía en general). Muchos firmantes entienden estos subterráneos como espacios patrimoniales que hay que conocer y conservar, para que sirvan para la reflexión y la construcción de un futuro mejor, y como advertencia para las generaciones presentes y futuras para que apuesten decididamente por la negociación y la resolución pacífica de los conflictos.

También numerosos visitantes manifiestan su deseo de que no haya más guerras en el mundo, y consideran que la guerra no es cosa del pasado, ni propio únicamente de la historia de nuestro país, sino que ha sido y es una constante en la historia de la humanidad, de ahí que aparezcan muchas referencias a los conflictos actuales (Palestina, Siria...) Por tanto, estos espacios no sólo generan conocimiento sobre el pasado sino que invitan a reflexionar sobre el presente y el futuro, y sobre conflictos que se desarrollan en diversas partes del planeta.

Una de las cuestiones más emotivas que aparecen en los libros de visita son las aportaciones de recuerdos familiares sobre el conflicto de numerosos visitantes. El refugio actúa así como un espacio que lleva a experimentar una especie de catarsis personal que permite rememorar el sufrimiento familiar. Es muy probable que la mayor parte de estas personas nunca hayan plasmado por escrito y de forma pública estas reflexiones.

Otra cuestión cultural (respeto y reconocimiento de las diferencias) es la apuesta que realizan numerosos mensajes que abogan por una reconciliación nacional, por la desaparición de los bandos y las divisiones entre izquierdas y derechas, con el objetivo de que no se vuelva a repetir la peor de las guerras, la que enfrenta a ciudadanos de un mismo país. No obstante, algunas aportaciones señalan algunas de las causas que -según ellos- impiden esa reconciliación: que mientras los vencedores de la guerra están localizados y enterrados dignamente, los perdedores yacen en cunetas y fosas comunes, y no despiertan el mayor interés por revertir la situación entre las autoridades de nuestro país.

Ejemplos:

“Ojalá que no volvamos a utilizar estos lugares”.

"Qué este refugio sólo sirva de visita turística".

"Qué no haya que entrar por necesidad”.

“Tengo 9 años. Quiero que haya paz en todo el mundo”.

“Sí a la paz, no a la guerra”.

"Pablo estuvo aquí. No le gustan las bombas ni las guerras".

“Tengo 10 años y nunca he vivido una guerra ni la quiero vivir".

"Visita interesante que nos volvió a recordar la importancia de la convivencia en Paz entre todos los seres humanos, seamos de donde seamos y tengamos las ideas que tengamos”.

“No volvamos a matar por seguir a unos políticos miserables”. 
“Que la historia y el patrimonio nos enseñe a convivir y a no cometer errores”.

"Estos lugares deben ser conservados como ejemplo de salvajadas que no se pueden repetir".

"El espacio es de paz y pensamiento, no lo olvidemos y conservemos".

Algunos de los firmantes componen verdaderas poesías -algunas tomadas de autores consagrados- en su deseo de que no haya más enfrentamientos en el mundo.

"Las guerras para los cobardes, las palabras y los hechos de los valientes".

"Porque merece la pena morir por lo que no merece la pena vivir".

“Tus pies pisaron en guerra, los míos pisan en paz”.

"Nuestras mejores armas nuestras sonrisas".

"Debería desaparecer la palabra guerra de todos los diccionarios, de todas las lenguas".

"La guerra es una masacre, entre gente que no se conoce, para provecho de gente, que sí se conoce pero no se masacra".

"La Tierra es un sólo país y la humanidad sus ciudadanos”.

"En recuerdo de todas las víctimas de las guerras pasadas y presentes".

“¡Qué pena que tanta gente aún hoy esté sufriendo a causa de otras guerras!”.

"Un recuerdo a todas las víctimas y para los que aún lo viven. Siria-refugiados: la vergüenza de Europa”.

"Nunca debería haber en ningún lugar de la tierra las guerras, las peleas, la sangre, la tristeza”.

“En recuerdo a mis tías Clara y María que fallecieron en esta guerra de hermanos”.

"Porque nunca debiste estar aquí, ni tú ni nadie. Te quiero Abuela”.

“A la memoria de mi abuelo Ambrosio".

"Cuantas lágrimas de mi familia por culpa de la guerra”.

“Qué este refugio no divida más a las personas (izquierdas y derechas), sino los una. La guerra siempre es una locura y un error”.

"No hay mayor tragedia que el derramamiento de sangre entre hermanos".

"Viva España unida”.

"No más bandos. Una sola raza: Humanidad".

"Los bandos son los que hacemos nosotros: no existen".

"Descansen en paz todas las víctimas de la barbarie, independiente del bando que ocupen. No hay bandos en los corazones”.

Por último, dentro de esta categoría de análisis y respecto a las características o rasgos propios de lo que reconocemos como educación para la participación podemos destacar el fomento de los valores y principios democráticos, la pertenencia a una ciudadanía planetaria que está implicada con la paz y la defensa de los derechos humanos, el compromiso de emotividad y la consideración de estos espacios patrimoniales -bélicos- como espacios de formación ciudadana y transformación social.

\section{PROPUESTAS DE MEJORA SOBRE LA MUSEALIZACIÓN Y VISITA DEL ESPACIO}

La participación ciudadana se pone de manifiesto -muy especialmente- en las recomendaciones que realizan los visitantes para mejorar la musealización y visita del espacio, tanto para el discurso expositivo, los recursos didácticos utilizados y el horario de apertura, que pueden y deben mejorar la adquisición de conocimientos: se propone incluir una recreación audiovisual con sonidos sobre los bombardeos aéreos; una mejora en la división por temáticas de las galerías; la inclusión de algún material o contenido que se echa en falta (por ejemplo un listado con los represaliados tras el bombardeo), e incluso, algunas personas advierten de algunos errores en los nombres y apellidos de los fallecidos durante el ataque rebelde. Asimismo, se plantea la 
necesidad de establecer un horario fijo y estable para poder visitar el refugio de la Plaza de Santiago.

Por otro lado, queremos proponer una serie de medidas y actuaciones para conseguir que la ciudadanía se implique en el conocimiento, conservación y revalorización de los refugios de la guerra civil en Jaén: mantener y ampliar el programa de visitas escolares que oferta la concejalía de Turismo del Ayuntamiento de Jaén; ofertar desde la Universidad de Jaén visitas y materiales didácticos destinados a toda la ciudadanía y muy especialmente a los centros escolares, para que el espacio y su contenido puedan ser trabajados; organización de jornadas científicas que sirvan para dar a conocer el espacio desde diferentes puntos de vista (histórico, arqueológico, arquitectónico...); abrir el espacio -como hasta ahora se ha hecho- para que colectivos ciudadanos (artistas, fotógrafos...) puedan interpretarlo y ofrecer una visión nueva y diferente del mismo; organizar concursos (dibujo, poesía, fotografía...) para que los visitantes, especialmente los escolares, ofrezcan su percepción del espacio visitado; y por último, abrir un debate ciudadano en la ciudad sobre la conservación y apertura de los refugios que se localicen en el futuro.

\section{CONCLUSIONES}

La mayor parte de las cuestiones que entendemos integrantes de la participación ciudadana (compromiso para la acción y la transformación social, fomento de los principios y valores democráticos, ciudadanía planetaria comprometida con los derechos humanos, compromiso con la igualdad y la justicia social, compromiso e interés por el conocimiento histórico, o el compromiso de emotividad) aparecen reflejadas en las categorías analizadas. Podemos inferir que la visita al Refugio de la Plaza de Santiago de Jaén fomenta la participación ciudadana, porque las reflexiones manifestadas expresan los anhelos de la ciudadanía sobre este espacio patrimonial: se aboga por su protección y conservación, su apertura al público, porque se consideran lugares de aprendizaje, de enseñanza sobre nuestro pasado histórico, y como advertencia para las generaciones presentes y futuras. Además, siguiendo la línea marcada por autores como De Alba y Lucas (2017, p. 30) para quienes los visitantes, al conocer estos espacios, desarrollan habilidades como la empatía y el pensamiento crítico "destrezas tan necesarias para un ciudadano participativo y comprometido socialmente”, este tipo de patrimonio fomenta la formación y la construcción de una ciudadanía global, comprometida con los principios y valores democráticos.

En relación al principio de emotividad, hay que afirmar que la visita favorece la implicación de la ciudadanía y los escolares, en la gestión y conservación del patrimonio.

Por otro lado, aunque el análisis realizado no ha disociado las expresiones manifestadas por grupos de edades ni culturales, podemos afirmar que la sociedad española es cada vez más consciente del papel protagonista y activo que tiene que adoptar en la sociedad democrática y ciudadana del siglo XXI. Se pide y exige a los poderes políticos y a quienes toman decisiones sobre nuestro patrimonio, que hagan lo necesario para que estos vestigios no desaparezcan y puedan ser visitados, porque estimulan la reflexión sobre nuestro pasado, el cual proyecta sus lecciones sobre el presente y el futuro. No sabemos hasta qué punto, pero creemos que podemos afirmar que se está produciendo un empoderamiento de la sociedad civil de nuestro país.

Y por último, consideramos que el fomento de la participación ciudadana es una necesidad y una obligación en la escuela actual. Como señalan García Pérez y otros: "La escuela del siglo XXI no puede permitirse el lujo de no plantearse de forma explícita la educación para la participación ciudadana como una finalidad básica...constituyendo una excelente oportunidad para asumir, de esta forma, un compromiso activo con los problemas de nuestro mundo” (p. 9). Además, no debemos limitarnos a la escuela y los ámbitos académicos como los únicos entornos desde los que trabajar y fomentar esta participación, sino que debemos buscar la conexión y colaboración entre la educación formal, no formal e informal. 


\section{Referencias}

Ayán Vila, X. (2015). Altamira vista por los españoles. Madrid: JAS Arqueología editorial.

Bañón, A. M. (2008). El análisis crítico del discurso y su aprovechamiento en el aula. Textos de Didáctica de la Lengua y de la Literatura, 49, 28-47.

De Alba Fernández, N., García Pérez, F. y Santisteban Fernández, A. (2012). Introducción. Educar para la participación ciudadana en la enseñanza de las Ciencias Sociales. En N. De Alba Fernández, F. García Pérez y A. Santisteban Fernández (eds.), Educar para la participación ciudadana en la enseñanza de las Ciencias Sociales (pp. 13-16). Sevilla: AUPDCS.

De Alba Fernández, N. y Lucas, L. (2017). Educación patrimonial para formar ciudadanos críticos. Íber, 89, 26-31.

Feliu Torruella, M. y Hernández Cardona, F. X. (2013). Didáctica de la Guerra Civil Española. Barcelona: Graó.

García Pérez, F.F. (2009). Educar para la participación ciudadana. Un reto para la escuela del siglo XXI. Investigación en la escuela, 68, 5-10.

García Pérez, F.F. y De Alba Fernández, N. (2007). Educar en la participación como eje de una educación ciudadana. Reflexiones y experiencias. Didáctica Geográfica, 9, 243-258.

García Pérez, F.F. y Moreno, O. (2013). Educar para la participación desde una perspectiva planetaria. Íber, 74, 9-16.

Llonch, N. y Santacana, J. (2011). Claves de la museografía didáctica. Lleida: Milenio.

López Facal, R. (2011). Aprender de los conflictos. Íber, 69, 5-7.

Lucas, L. y Estepa, J. (2016). Identidad, valores cívicos y participación ciudadana en la didáctica del patrimonio. Aprendizaje y enseñanza. En S. Molina Puche, A. Escribano-Miralles y J. Díaz-Serrano (eds). Patrimonio, identidad y ciudadanía en la enseñanza de las ciencias sociales (pp. 89-100). Murcia: Universidad de Murcia.

Rojo Ariza, M. C., Cardona Gómez, G., Romero Serra, M., Feliu Torruella, M., Jiménez Torregrosa, L., Iñíguez Gràcia, D. y Hernández Cardona, X.F. (2014). Patrimonio, conflicto y relevancia histórica. Una experiencia formando a los futuros profesionales de la educación. CLIO. History and History teaching, 40.

Sant Obiols, E. y Pagès Blanch, J. (2012). Los conocimientos históricos y actuales para el aprendizaje de la participación como base de una ciudadanía crítica y activa. En N. De Alba Fernández, F. García Pérez y A. Santisteban Fernández (eds.), Educar para la participación ciudadana en la enseñanza de las Ciencias Sociales (pp. 363-372). Sevilla: AUPDCS.

Sodaro, M. J. (2004). Política y Ciencia Política. Una introducción. Aravaca (Madrid): McGrawhill.

UNESCO (1982). Líneas Generales. Recuperado de http://www.unesco.org/new/es/mexico/workareas/culture/ [14 de febrero de 2018]

Van Dijk, T. A. (1999). El análisis crítico del discurso. Anthropos, 186, $23-36$.

Van Dijk, T. A. (2016). Análisis crítico del discurso. Revista Austral de Ciencias Sociales, 30, 203222.

Vera Deleito, A. y Vera Deleito Aparici, J. (2000). Defensa Antiaérea republicana (1936-1939). Artillería, refugios (algo de valor). Edición de Jorge Vera de Leito Aparici.

CÓMO CITAR ESTE ARTÍCULO

Jaén Milla, S. (2018). La Guerra Civil en los libros de visitas. Fuentes de conocimiento sobre formación y participación ciudadana. Didáctica de las ciencias experimentales y sociales, 34, 3548. DOI: 10.7203/DCES.34.10704. 
